Our results are not in agreement with those of a recent investigation of the role of bone cement as a releasing factor for the genesis of fat embolism in cats (Dustmann et al., 1972). These workers also used Plasticine as a control substance and observed no haemodynamic disturbance when it was inserted. Details of the blood pressure changes were not given, but it was stated that in most cases when cement was inserted there was a fall in peripheral blood pressure and a rise in central venous pressure. Histological evidence of massive fat embolism was seen in the lungs in six out of eight experiments with cement and minimal fat embolism in all eight experiments with Plasticine. The reason for this difference in results is not known, though there were differences in operative and insertion techniques and in the anaesthetic agents used.

Several instances of cardiac arrest during or after insertion of the Thompson femoral head prosthesis in man were attributed to pulmonary fat embolism (Burgess, 1970; Dandy, 1971; Gresham et al., 1971) and a recent retrospective study identified this operation as entailing a special risk of death from this cause (Sevitt, 1972). The identification of fat and marrow cells in the femoral venous blood and lungs of a number of animals confirms the risk of embolism under experimental conditions. It is unlikely, however, that the acute hypotensive effect is caused by a factor carried in the blood since it occurred when the femoral venous return was prevented, and its onset was not delayed by the introduction of a $30-\mathrm{cm}$ shunt. A delay of at least five seconds would be expected on the basis of measurements of femoral venous flow. On four of the five occasions when blood was collected from the femoral vein draining the limb subjected to Plasticine insertion, there was no change in arterial pressure on reinfusion of this blood a few seconds later. In one experiment, however, there was a protracted fall in blood pressure accompanied by a rise in central venous pressure. The release of fat, marrow cells, or other materials into the circulation was a common occurrence judging from the histological examination of the lungs and femoral venous blood. Probably this was responsible for the occasional observations of protracted cardiovascular events, but the acute falls in blood pressure which occurred on almost every occasion may have been reflex in nature. The possibility should be considered that the hypotensive episodes which appear common after cement insertion in man (Harris, 1970; Ling and James, 1971; Phillips et al., 1971; Thomas et al., 1971) have a different pathogenesis from that leading to the relatively rare cases of cardiac arrest.

In conclusion, this animal preparation gives a reproducible acute fall in arterial blood pressure in circumstances similar to the operative situation in man and the results suggest that the mode of implantation is more important than the material implanted. Experiments ore in progress to further elucidate the nature of the depressor effect and the means of preventing it. These experiments will be reported in detail later.

We thank Dr. R. F. Crampton, Director of B.I.B.R.A., for his suggestions and comments on the paper. Also we are grateful to $\mathrm{Dr}$. P. Grasso for his opinion on the tissue pathology, and for his advice and encouragement.

\section{References}

Burgess, D. M. (1970). British Medical fournal, 3, 588.

Cadle, D., et al. (1972). British Medical fournal, 4, 107

Charnley, J. (1970). In Acrylic Cement in Orthopaedic Surgery. Edinburgh, Livingstone.

Cohen, C. A., and Smith, T. C. (1971). Anesthesiology, 35, 547.

Dandy, D. M. (1971). Injury, 3, 85.

Deichmann, W. (1941). Fournal of Industrial Hygiene and Toxicology, 23, 343.

Dustmann, H. O., Schulitz, K. P., and Koch, H. (1972). Archiv für orthopädische und Unfall-Chirurgie, $72,114$.

Ellis, R. H., and Mulvein, J. (1972). British Medical fournal, 2, 528.

Frost, P. M. (1970). British Medical fournal, 3, 524.

Gresham, G. A., Kuczynski, A., and Rosborough, D. (1971). British Medical Fournal, 2, 617.

Harris, N. H. (1970). British Medical fournal, 3, 523.

Homsy, C. A Tulios, H. S Anderson, M. S and Diferrante, N. M. (1969). Paper presented at Orthopaedic Research Society Meeting, New York, 17 January 1969. Cited by Charnley (1970).

Homsy, C. A., Tullos, H. S., Anderson, M. S., Diferrante, N. M., and King, J. W. (1972). Clinical Orthopaedics and Related Research, 83, 317.

Hyland, J., and Robins, R. H. C. (1970). British Medical fournal, 4, 176.

Ling, R. S. M., and James, M. L. (1971). British Medical fournal, 2, 404.

Newens, A. F., and Volz, R. G. (1972). Anesthesiology, 36, 298.

Peebles, D. J., Ellis, R. H., Stride, S. D. K., and Simpson, B. R. J. (1972) British Medical fournal, $1,349$.

Phillips, H., Cole, P. V., and Lettin, A. W. F. (1971). British Medical fournal, 3, 460 .

Powell, J.: N., McGrath, P. J., Lahiri, S. K., and Hill, P. (1970). British Medical fournal, 3, 326.

Sevitt, S. (1972). British Medical fournal, 2, 257.

Thomas, T. A., Sutherland, I. C., and Waterhouse, T. D. (1971). Anaesthesia, 26, 298.

\title{
"On-Off" Phenomena Related to High Plasma Levodopa
}

\author{
L. E. ClAveria, D. B. CALNE, J. G. ALLEN
}

British Medical fournal, 1973, 2, 641-643

\section{Summary}

The neurological deficit and plasma concentrations of levodopa have been studied in a Parkinsonian patient experiencing "on-off" phenomena. Blind evaluations of transient attacks of dysphonia revealed an association between episodes of neurological deterioration and exceptionally high plasma concentrations of levodopa shortly

\footnotetext{
Department of Medicine (Neurology), Royal Postgraduate Medical School, London W12 OHS

L. E. CLAVERIA, L.M.S., Research Fellow

D. B. CALNE, D.M., M.R.C.P., Consultant Neurologist

Roche Products Ltd., Welwyn Garden City, Herts

J. G. ALLEN, PH.D., B.SC., Senior Biochemist
}

after ingestion. These results indicate that "on-off" phenomena can be toxic reactions to levodopa rather than deteriorations due to inadequate intake or absorption of the drug. Management of patients subject to such attacks should be aimed at minimizing fluctuations in the serum level of the drug.

\section{Introduction}

Rapid spontaneous fluctuation of symptoms and signs has long been recognized as a characteristic feature of the Parkinsonian syndrome. The commonest manifestations are the exacerbations of tremor which occur when a patient is anxious and the transient episodes which suddenly freeze a patient to immobility when walking. Since the introduction of levodopa, oscillations in performance, often termed as the "on-off" effect or akinesia paradoxica, have been reported with increasing frequency (Cotzias et al., 1969; Barbeau et al., 1971; Barbeau, 1972; McDowell, 1972; Markham, 1972; Yahr, 1972; Damasio et al., 
1973). These attacks comprise a more profound and prolonged motor deficit than those encountered before treatment with levodopa. Akinesia is the predominant feature, commonly accompanied by distress. There may be a reduction or less often an increase in muscle tone. Hyperkinesia, tremor, and confusion have been reported. Several patients have also complained of a hot flushing sensation in these attacks. "On-off" phenomena develop over a few minutes, and clear spontaneously over a similarly dramatic short time course. They usually last between 30 minutes and three hours and often recur at the same time each day. It has been suggested that they are commonest in patients who have been taking rather high doses of levodopa for long periods, at least 18 months. Those who initially respond well to therapy are more likely to encounter this problem. Damasio et al. (1973) reported a prevalence of "on-off" phenomena of nine out of 100 . As their mechanism is not known, a rational approach to their management has not been formulated.

In this study clinical observations were correlated with estimations of the plasma concentration of levodopa in a single patient experiencing frequent "on-off" attacks. As the main motor manifestation of her neurological deterioration was dysphonia, it was possible to record her voice on magnetic tape and subsequently assess the severity of disability in a blind situation in which the evaluator had no knowledge of the time at which the various recordings were made.

\section{Patient and Methods}

The patient was a woman of 67 years. There was no history of encephalitis or exposure to drugs producing Parkinsonism. She had no relatives with Parkinsonism. In 1959 she developed tremor of her right hand. In 1960 an expressionless facies and minimal resting tremor in the left hand were noted. A diagnosis of idiopathic Parkinsonism was made and stereotactic surgery was performed on the right thalamus in 1961 with noticeable improvement of the tremor in her left hand. In 1962 a similar operation was performed on the left thalamus but this was followed by a dense right hemiplegia which persisted. Over the next 10 years slow deterioration occurred, with increased rigidity in all four limbs and pronounced hypokinesia.

In August 1970 she was started on levodopa therapy, achieving a maximum tolerated dose of $6.25 \mathrm{~g}$ a day over five months. At this stage the only adverse reactions were occasional nausea and minimal postural hypotension. In October 1971 episodes of confusion occurred and the dose was reduced to $5 \mathrm{~g}$ a day. Her Parkinsonian features had greatly improved but she complained of attacks of flushing, and in September 1972 she was started on propranolol $20 \mathrm{mg}$ daily which led to some improvement in this symptom.

In January 1973 her husband noticed a sudden deterioration in her condition with frequent episodes of dysphonia and confusion. These attacks tended to occur after lunch and lasted from one to four hours. No dyskinesia was encountered. The patient was taken into hospital. The day after admission oral levodopa $(1.0 \mathrm{~g})$ was administered during breakfast (8 a.m.) and lunch (12 noon). Full neurological examination was performed at hourly intervals, grading her deficits according to an arbitrarily defined clinical scoring protocol (0 representing normality; 4 maximal deficit) as described by Calne et al. 1971 . Every hour her voice was recorded on magnetic tape (Uher Universal 5000 , tape speed $3 \frac{3}{4}$ in $(7.7 \mathrm{~cm})$ per second). At each recording she repeated standard words, with a request that she speak as loudly and clearly as possible. Her speech was sub- sequently evaluated, zero score representing normal volume and articulation. Maximum disability, where difficulty was encountered in deciding whether the patient's voice emerged above the noise level of the recording system, was given a score of 4.

Over the day that clinical assessments were made, samples of venous blood were taken at hourly intervals. The blood was centrifuged in tubes containing heparin and sodium metabisulphite. The amino-acid fraction was separated on a Dowex column, oxidized to hydroxy-indole derivatives, and assayed fluorimetrically for levodopa as described by Reid et al. (1972).

\section{Results}

Clinical evaluations of mental state, facial movement, finger dexterity, tone, power, and tendon reflexes showed only two trends. Confusion and facial hypokinesia were both increased at 1 p.m. and 2 p.m.

The time course of fluctuations in dysphonia is shown in the table. The figures represent the evaluations by two independent "blind" observers assessing a series of eight tape recordings of the voice. There is close similarity between the figures obtained by the two assessors.

The plasma concentrations of levodopa are shown in the graph, together with the mean values obtained in another study
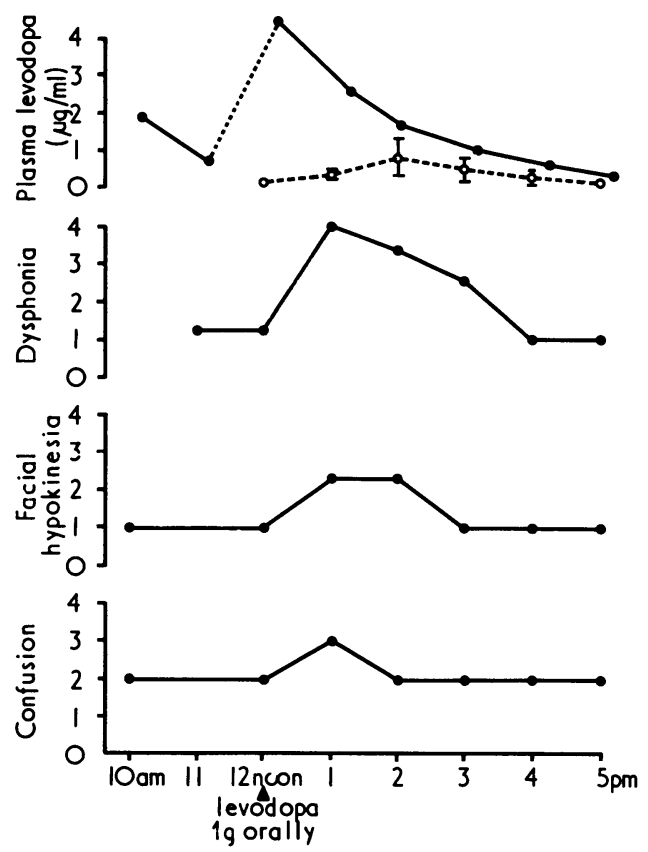

Sequential observations on plasma levodopa, dysphonia, facial hypokinesia, and confusion (increasing scores signify increasing deficit). One gramme of levodopa was taken by mouth at $8 \mathrm{a} . \mathrm{m}$. and 12 noon. Dotted line indicates continuity of levodopa level; the rise must have followed rather than preceded noon dose. Broken line is derived from mean plasma levels reported by Dunner et al. (1971) in five depressed patients given an isolated dose of $1 \mathrm{~g}$ of levodopa; bars represent standard errors.

by Dunner et al. (1971). Three points emerge from a comparison of these observations. First, the exceptionally rapid absorption in our patient-an oral dose of $1 \mathrm{~g}$ taken between lunch courses

"Blind" Evaluations of dysphonia by Two Observers. Last Set of Values are Based on Recordings made Four Weeks Later, Levodopa Therapy having been stopped.

\begin{tabular}{|c|c|c|c|c|c|c|c|c|c|c|c|c|}
\hline & & & & Time: & 11 a.m. & 12 noon & 1 p.m. & 2 p.m. & 3 p.m. & 4 p.m. & 5 p.m. & Four Weeks Later \\
\hline $\begin{array}{l}\text { 1st observer } \\
\text { 2nd observer }\end{array}$ & $\therefore$ & $\therefore$ & $\begin{array}{l}. \\
\therefore\end{array}$ & $\ldots$ & $1 \cdot 5$ & $\begin{array}{l}1 \\
1 \cdot 5\end{array}$ & $\begin{array}{l}4 \\
4\end{array}$ & $3 \cdot 5$ & $\begin{array}{l}2.5 \\
2.5\end{array}$ & 1 & 1 & $\begin{array}{l}0 \\
0\end{array}$ \\
\hline
\end{tabular}


at 12 noon leading to a rise from $0.85 \mu \mathrm{g} / \mathrm{ml}$ at 11.15 a.m. to $4.32 \mu \mathrm{g} / \mathrm{ml}$ at $12.15 \mathrm{p} . \mathrm{m}$. The second unusual feature is the high peak concentration of levodopa, $4.32 \mu \mathrm{g} / \mathrm{ml}$. A third point of contrast is the prolonged plasma half life of levodopa in our patient, 1.57 hours compared with 1.08 hours.

The mean scores for dysphonia, confusion, and facial hypokinesia are also indicated in the graph. It is evident that high plasma concentrations correlate with maximal deficit in all clinical features.

After these investigations levodopa therapy was stopped, and orphenadrine (50 $\mathrm{mg}$ thrice daily) was given. It is notable that the episodes of dysphonia and confusion cleared completely over four weeks without any general deterioration in her Parkinsonism.

\section{Discussion}

The "on-off" phenomenon has become recognized as a problem of increasing importance over the last year. Its relatively recent emergence can be explained in terms of prolonged periods of therapy usually completed before its appearance. Attacks are particularly distressing when, as often occurs, they develop in patients who had done well on levodopa. No satisfactory approach to their management has been reported.

The simplest explanation for a dramatic increase in hypokinesia in patients receiving levodopa would be inadequate intake or absorption of the drug. The findings reported here indicate that it is more likely that the attacks represent a toxic reaction to levodopa or one of its metabolites. This view would be consonant with the reported association of these hypokinetic episodes with certain known adverse reactions to levodopa such as confusion and hyperkinesia, which are also accompanied by high plasma concentrations of levodopa. Furthermore, the higher prevalence of "on-off" phenomena in patients who have been on treatment with high doses for prolonged periods is in accord with the view that a build-up of levodopa or one of its metabolites is responsible.

While the mechanism of levodopa toxicity in these episodes is not known, Hornykiewicz (1973) has made a suggestion, entirely compatible with our observations, that a metabolite of levodopa is acting as a "partial agonist" or "false transmitter" in the central nervous system.

One feature of interest in the patient studied here was the extremely rapid absorption of levodopa. As the plasma half life was prolonged, it is possible that either metabolism was impaired or distribution was abnormal. In patients who develop "on-off" attacks, therefore, unusual pharmacokinetics may prove to be a contributing factor.

Having obtained this evidence that "on-off" phenomena are related to excessive plasma concentrations of levodopa, certain practical implications should be considered. When starting patients on levodopa it may be unwise to increase the dose to maximum tolerated levels in all cases. Barbeau (1972) also concluded from clinical observations that "on-off" attacks represent levodopa toxicity, and he has suggested that an arbitrary upper dose limit around $4.0 \mathrm{~g}$ a day should be set for routine therapy until further evidence is available.

In addition to preventing attacks there is the problem of managing patients in whom these episodes are established. It is evident that unless the excessive peaks of plasma levodopa can be reduced by more frequent administration of smaller doses the total daily intake of levodopa should be decreased. The addition of peripheral decarboxylase leads to less extreme fluctuations in the plasma concentration of levodopa through the day, but mean plasma concentrations tend to be rather higher so it is not possible to predict how "on-off" phenomena will be affected.

This study was supported by the Medical Research Council.

\section{References}

Barbeau, A., Gillo-Joffroy, L., and Mars, H. (1971). Clinical Pharmacology and Therapeutics, 12, 353 .

Barbeau, A. (1972). In Proceedings of the 4th International Symposium on Parkinson's Disease, ed. J. Siegfried. Bern, Huber.

Calne, D. B., et al. (1971). British Medical fournal, 3, 729.

Cotzias, G. C., Papavasiliou, P. S., and Gellene, R. (1969). New England Fournal of Medicine, 280, 337.

Damasio, A. R., Castro-Caldas, A., and Levy, A. (1973). In Progress in Parkinsonism, ed. D. B. Calne. New York, Raven Press.

Dunner, D. L., Brodie, H. K. H., and Goodwin, F. K. (1971). Clinical Pharmacology and Experimental Therapeutics, 12, 121.

Hornykiewicz, O. (1973). In Treatment of Parkinson's Disease-The Role of Dopa Decarboxylase Inhibitors, ed. M. D. Yahr. New York, Raven Press. McDowell, F. (1972). Neurology, 22, 24.

Markham, C. H. (1972). Neurology, 22, 17.

Reid, J. L., Calne, D. B., Vakil, S. D., Allen, J. G., and Davies, C. A. (1972). Fournal of the Neurological Sciences, 17, 45.

Yahr, M. D. (1972). In Proceedings of the 4th International Symposium on Parkinson's Disease, ed. J. Siegfried. Bern, Huber.

\section{PRELIMINARY COMMUNICATIONS}

\section{Immunoglobulin Deposition in Liver of Patients with Active Chronic Hepatitis and Antibody against Smooth Muscle}

\author{
R. L. DAWKINS, R. A. JOSKE
}

British Medical fournal, 1973, 2, 643-645

\section{Summary}

Liver biopsies from 33 patients with miscellaneous liver diseases were studied by direct immunofluorescence.

University Departments of Pathology and Medicine, Royal Perth Hospital, Perth, Western Australia, 6000

R. L. DAWKINS, Clinical Immunologist and Senior Lecturer in Pathology R. A. JOSKE, Professor of Medicine
Three patients with active chronic hepatitis possessed a distinctive pattern of staining with anti-IgG conjugate. They were relatively young women and all three possessed the anti-smooth-muscle antibody. In addition, all three were untreated at the time of study. It is suggested that direct immunofluorescence on liver biopsies may help in the investigation of liver disease and that humoral immunity may participate in the pathogenesis of active chronic hepatitis.

\section{Introduction}

Active chronic hepatitis was first delineated as a distinct entity because of its association with the lupus erythematosus (L.E.) cell (Joske and King, 1955). Since then several immunological abnormalities have been described but the pathogenesis of this syndrome remains uncertain. The finding of anti-smoothmuscle antibody suggests that humoral immunity could be involved, but the relation between a smooth muscle antigen and 